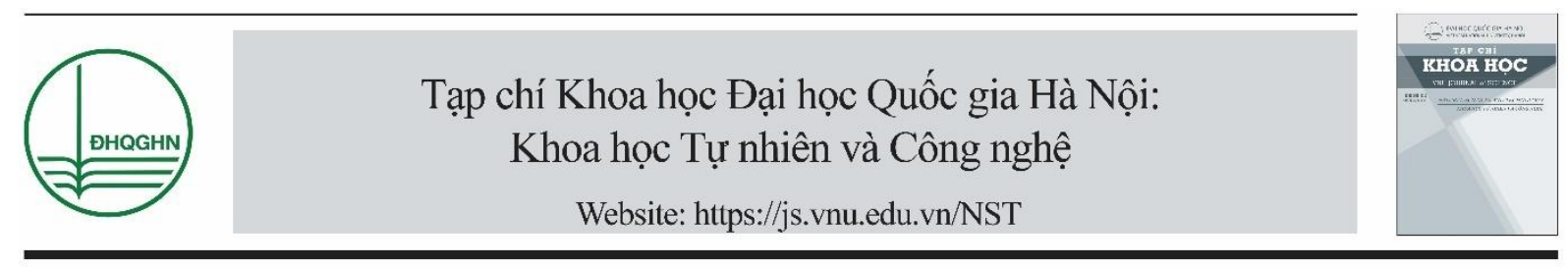

\title{
Đa hình trình tự promoter của gen $C Y P 2 E 1$ ở đối tượng công nhân ngành sản xuất sơn bị phơi nhiễm với dung môi hữu cơ
}

\author{
Nguyễn Thị Hiền ${ }^{1,2}$, Đỗ Thị Cẩm Nhung ${ }^{1,2}$, Nguyễn Phú Hùng ${ }^{3}$, \\ Nguyễn Thị Hồng Vân ${ }^{1}$, Bùi Phương Thuận ${ }^{1}$, Nguyễn Quang Huy ${ }^{1, *}$ \\ ${ }^{1}$ Khoa Sinh hoc, Truờng Đại học Khoa hoc Tụ nhiên, ĐHQGHN, \\ 334 Nguyễn Trãi, Thanh Xuân, Hà Nội, Việt Nam \\ ${ }^{2}$ Viện Khoa học An toàn và Vệ sinh Lao động, 99 Trần Quốc Toản, Hà Nội, Việt Nam \\ ${ }^{3}$ Truòng Đại học Khoa học, Đại học Thái Nguyên, Phưòng Tân Thịnh, Thái Nguyên, Việt Nam \\ Nhận ngày 17 tháng 10 năm 2018 \\ Chỉnh sửa ngày 12 tháng 12 năm 2018; Chấp nhận đăng ngày 13 tháng 12 năm 2018
}

\begin{abstract}
Tóm tắt: CYP2E1 là gen mã hóa enzym CYP2E1 đóng vai trò quan trọng trong quá trình chuyển hóa của nhiều hợp chất hữu cơ được dùng phổ biến trong công nghiệp như benzen, toluen, xylen, styren $(\mathrm{B}, \mathrm{T}, \mathrm{X}, \mathrm{S})$. Sự xuất hiện các biến thể trên vùng promoter của gen $C Y P 2 E 1$ có thể dẫn tới sự thay đổi mức độ biểu hiện của gen và tiến triển của một số bệnh ở đối tượng phơi nhiễm với dung môi hữu cơ. Trong nghiên cứu này, chúng tôi phân tích các điểm đa hình trên đoạn promoter của gen $C Y P 2 E 1$ ở 118 người bao gồm 73 công nhân làm việc tại công ty sản xuất sơn bị phơi nhiễm với dung môi hữu cơ và 45 công nhân may không bị phơi nhiễm (đối chứng) thông qua phương pháp PCR và giải trình tự. Kết qủa ban đầu cho thấy, đã khuếch đại được trình tự DNA đoạn promoter của gen $C Y P 2 E 1$ trên tất cả các mẫu và phát hiện được 4 điểm đa hình bao gồm $3739 \mathrm{G}>\mathrm{C}, 3519 \mathrm{~T}>\mathrm{G}, 3468 \mathrm{~T}>\mathrm{A}$ và $3620 \mathrm{C}>\mathrm{T}$. Phân tích thống kê cho thấy không có sự khác biệt có ý nghĩa về phân bố của các đa hình trong nhóm phơi nhiễm dung môi hữu cơ và nhóm đối chứng, nhưng kiểu gen liên quan đến promoter của CYP2E1 là không đồng nhất giữa các đối tượng được nghiên cứu.
\end{abstract}

Tù khóa: Đa hình đơn nucleotide, CYP2E1, phơi nhiễm dung môi hữu cơ.

\section{Mở đầu}

Dung môi hữu cơ là hỗn hợp hóa học phức tạp có chứa nhiều loại hydrocarbon khác nhau

\footnotetext{
*Tác giả liên hệ. ĐT: 84-904263388.

Email: nguyenquanghuy@vnu.edu.vn

https://doi.org/10.25073/2588-1140/vnunst.4816
}

như alkan, rượu, xeton, andehit, este và các phân tử thơm nhỏ, bay hơi và tích hợp vào môi trường không khí tạo thành các hợp chất hữu cơ dễ bay hơi (VOCs). VOCs nói chung và đặc biệt là benzen, toluen, xylen, styren $(\mathrm{B}, \mathrm{T}, \mathrm{X}, \mathrm{S})$ nói riêng với đặc điểm về khả năng hòa tan và độ bay hơi cao VOCs có chứa toluen, xylen được dùng chủ yếu trong các ứng dụng như sản 
xuất nhựa tổng hợp, sản xuất sơn, keo dán... Những người làm việc trong môi trường này có nguy cơ tổn hại đến sức khỏe như gây độc thần kinh, suy giảm khả năng sinh sản, tổn thương gan và thận, suy hô hấp, viêm da...

Cytochrome P450 là một nhóm các enzym có vai trò quan trọng trong quá trình chuyển hóa của rất nhiều chất sinh học và các hợp chất nội sinh bao gồm thuốc, thực phẩm chức năng, dung môi dùng trong công nghiệp và các chất gây ô nhiễm thành các dạng chuyển hóa [1]. Ngoài ra chúng còn tham gia vào quá trình ô-xi hóa, xúc tác sự hoạt hóa các tiền chất gây ung thư thành dạng cuối gây ung thư. Trong đó, CYP2E1 đóng vai trò quan trọng trong quá trình chuyển hóa của phần lớn các hợp chất có khối lượng phân tử nhỏ được sử dụng trong dung môi công nghiệp (như ethanol, acetone và chloroform), thuốc (như acetaminophen, isoniazid, chlorzoxazone, trimethadione và $\mathrm{d}$ benzphetamine), tiền chất gây ung thư (benzen, $\mathrm{N}$-nitrosodimethylaminen, và styren) [2-4]. Bên cạnh đó, các đa hình di truyền trên gen $C Y P 2 E 1$ cũng đã được nghiên cứu và chỉ ra được vai trò quan trọng của các đa hình trong sự biến thiên liên tục trong phản ứng của thuốc, sự tương tác giữa thuốc với thuốc và trong độ nhạy cảm của bệnh do hóa chất $[5,6]$. Đa hình nằm trên vùng điều hòa của gen $C Y P 2 E 1$ ảnh hưởng đến sự liên kết của các nhân tố phiên mã và làm thay đổi sự điều hòa phiên mã. Những sự thay đồi này có thể được giải thích thông qua mức độ biểu hiện của $C Y P 2 E 1 \mathrm{mRNA}$ [7]. Tuy nhiên cơ chế điều hòa phiên mã của gen $C Y P 2 E 1$, đặc biệt là trên cơ thể người chưa được rõ ràng và cần được nghiên cứu thêm. Trong nghiên cứu này, chúng tôi phân tích các đa hình điểm trên một đoạn promoter của gen $C Y P 2 E 1$ ở 118 đối tượng nghiên cứu (73 công nhân bị phơi nhiễm với dung môi hữu cơ đặc biệt là các hợp chất bay hơi (VOC) như benzen, toluen, xylen từ các công ty sản xuất sơn và 45 công nhân không bị phơi nhiễm từ công ty may) thông qua phương pháp khuếch đại gen và giải trình tự.

\section{2. Đối tượng và phương pháp nghiên cứu}

\section{1. Đối tượng và mẫu nghiên cưu}

Đối tượng nghiên cứu gồm 73 công nhân làm việc tại công ty sản xuất sơn phơi nhiễm với dung môi hữu cơ và nhóm đối chứng là 45 công nhân ngành may không phơi nhiễm với dung môi hữu cơ. $5 \mathrm{ml}$ máu tĩnh mạch của mỗi đối tượng tham gia nghiên cứu được cho vào ống đủ tiêu chuẩn có chứa chất chống đông EDTA. Mẫu sinh học sau khi lấy được bảo quản lạnh, sau đó được bảo quản $-80^{\circ} \mathrm{C}$ ở phòng thí nghiệm.

\subsection{Hóa chất}

Các hóa chất được sử dụng trong nghiên cứu bao gồm bộ kit tách chiết và tinh sạch DNA từ mẫu máu (GeneJET whole blood genomic DNA purification mini kit), hóa chất dùng để khuếch đại trình tự DNA đích (PCR master mix) và bộ kit dùng để tinh sạch sản phẩm $\mathrm{PCR}$ (GeneJET PCR Purification Kit) của hãng Thermo Fisher Scientific cung cấp.

\subsection{Phuoong pháp nghiên cúu}

\section{Tách chiết DNA tổng số tù máu}

$200 \mu 1$ máu của mỗi mẫu nghiên cứu được sử dụng để tách chiết và tinh sạch DNA tổng số. Quy trình tách chiết được thực hiện theo hướng dẫn của nhà sản xuất.

DNA tổng số thu được sau tách chiết sẽ được kiểm tra trên gel Agarose $1 \%$ bằng phương pháp điện di và được định lượng bằng phương pháp đo quang phổ bước sóng 260/280nm.

Khuếch đại và xác định trình tụ promoter của gen CYP2E1

DNA tổng số được sử dụng làm khuôn trong phản ứng khuếch đại gen bằng phương pháp $\mathrm{PCR}, 2$ đoạn mồi Promotor $1 \mathrm{~F}$ và Promotor $1 \mathrm{R}$ được thiết kế với mục đích nhân lên đặc hiệu 1 đoạn DNA với kích thước lý thuyết là $563 \mathrm{bp}$ trong vùng promoter của gen CYP2E1. Cặp mồi trên được thiết kế bởi Jungxiang Wan và cộng sự với trình tự, nhiệt độ bắt cặp được trình bày trong bảng $1[8]$. 
Bảng 1. Trình tự cặp mồi của phản ứng PCR

\begin{tabular}{llll}
\hline Mồi & Trình tự mồi $\left(5^{\prime}-3^{\prime}\right)$ & $\operatorname{Tm}\left({ }^{\circ} \mathrm{C}\right)$ & $\begin{array}{c}\text { Kích thước sản } \\
\text { phẩm PCR }\end{array}$ \\
\hline Promotor 1F & AAGCCAAGGCTTCAATTTCA & 56,1 \\
\hline Promotor 1R & GATGAGAAATGAAGAAAATAAAAGTCA & 55,3 & \\
\hline
\end{tabular}

Kỹ thuật PCR được thực hiện trên hệ thống Gene Amp® PCR system 9700 (Applied Biosystems, Mỹ). Một kỹ thuật PCR có thể tích $50 \mu 1$ bao gồm: $10 \mu$ l DNA (100ng); $5 \mu 1$ 10X buffer; $1 \mu \mathrm{l} \mathrm{dNTP}$ mix $(10 \mathrm{mM}) ; 1 \mu 1$ mỗi mồi có nồng độ $10 \mu \mathrm{M} ; 0,25 \mu 1$ enzyme Dream Taq polymerase $(5 \mathrm{U} / \mu \mathrm{l})$ và $31,75 \mu \mathrm{l} \mathrm{H}_{2} \mathrm{O}$ khử ion. Phản ứng khuếch đại được diễn ra trong điều kiện sau: $94^{\circ} \mathrm{C}$ trong 4 phút, $30 \mathrm{chu}$ kỳ với $94^{\circ} \mathrm{C}$ trong 45 giây, $63^{\circ} \mathrm{C}$ trong 60 giây, $72^{\circ} \mathrm{C}$ trong 120 giây, phản ứng $\mathrm{PCR}$ được kéo dài $72^{\circ} \mathrm{C}$ trong 5 phút, để hoàn thành quy trình. Sản phẩm PCR được tinh sạch bằng GeneJET PCR Purification Kit (Thermo Fisher Scientific) và kiểm tra bằng điện di trên gel agarose $1 \%$. Sản phẩm tinh sạch được giải trình tự bởi công ty FistBASE.

\section{Phân tích số liệu}

Sau khi giải trình tự, các trình tự được phân tích và so sánh với nhau và với trình tự trên ngân hàng gen GenBank mã số NG 008383.1. Đồng thời sử dụng phần mềm BioEdit, Excel 2013 và Chi-Square test để tính tần số của các alen và kiểu gen.

\section{Đạo đức trong nghiên cúu}

Đối tượng hoàn toàn tự nguyện tham gia vào nghiên cứu. Các thông tin cá nhân được đảm bảo bí mật.

\section{Kết quả và thảo luận}

\section{1. Đặc điểm chung của nhóm mẫu nghiên cứu}

Kết quả ở Bảng 2 cho thấy tuổi đời, tuổi nghề và tỉ lệ giới tính của nhóm tiếp xúc và nhóm không tiếp xúc là tương đương nhau. Sự khác biệt không có ý nghĩa thống kê về tuổi đời trung bình cũng như tuổi nghề trung bình của 2 nhóm (khi áp dụng phương pháp so sánh 2 giá trị trung bình với phương sai biêt trước). Nhóm tiếp xúc có tuổi nghề trung bình là $20 \pm 8,68$ gần tương đương với tuổi nghề trung bình của nhóm không tiếp xúc $18,22 \pm 5,48$. Tuổi đời trung bình của mỗi nhóm đều xấp xỉ 42 tuổi. Sự tương đồng giữa nhóm tiếp xúc và nhóm không tiếp xúc về tuổi đời và tuổi nghề đảm bảo tính khách quan cho việc đánh giá kết quả nghiên cứu.

Bảng 2. Đặc điểm chung của nhóm nghiên cứu

\begin{tabular}{lllllll}
\hline Phân loại & \multicolumn{2}{l}{ Nhóm tiếp xúc } & (73 người) & & \multicolumn{2}{l}{ Nhóm không tiếp xúc (45 người) } \\
\cline { 2 - 6 } & $\begin{array}{l}\text { Giá trị trung } \\
\text { binh }\end{array}$ & $\begin{array}{l}\text { Giá trị nhó } \\
\text { nhất }\end{array}$ & $\begin{array}{l}\text { Giá trị lớn } \\
\text { nhất }\end{array}$ & $\begin{array}{l}\text { Giá trị trung } \\
\text { bình }\end{array}$ & $\begin{array}{l}\text { Giá trị nhó } \\
\text { nhất }\end{array}$ & $\begin{array}{l}\text { Giá trị lớn } \\
\text { nhất }\end{array}$ \\
\hline Tuổi đời & $42,08 \pm 8,8$ & 24 & 57 & $41,9 \pm 8,22$ & 28 & 57 \\
Tuổi nghề & $20 \pm 8,68$ & 3 & 34 & $18,22 \pm 5,48$ & 8 & 28 \\
Giới & $\%$ & Số lượng (người) & $\%$ & Số lượng (người) \\
Nam & 72,61 & 53 & & 66,67 & 30 \\
Nữ & 27,39 & 20 & 33,33 & 15 \\
\hline
\end{tabular}

\subsection{Kết quả khuếch đại trình tụ đoạn promoter gen CYP2E1}

Kết quả điện di cho thấy, sản phẩm PCR là một băng duy nhất có độ dài 563bp. Kích thước đoạn DNA thu được là phù hợp với kích thước theo tính toán lý thuyết từ vị trí bắt cặp của các đoạn mồi trong vùng promoter của gen CYP2E1. Đối với các mẫu đối chứng âm thay DNA khuôn bằng nước thì không có sản phẩm 
PCR được khuếch đại. Kết quả này cho thấy đã khuếch đại thành công đoạn promoter đặc hiểu của gen $C Y P 2 E 1$, phù hợp với công bố của Wan [8].

\subsection{Giải trình tụ DNA và xác định đa hình đoạn promoter của gen CYP2E1}

Trong nghiên cứu này, trình tự gen $C Y P 2 E 1$ có mã số NG_008383.1 trên Genbank được sử dụng làm trình tự tham chiếu để so sánh với 118 trình tự DNA của các mẫu nghiên cứu. Kết quả so sánh cho thấy, có 4 điểm đa hình trên vùng promoter của $C Y P 2 E 1$ được phát hiện. Những vị trí đa hình tìm được bao gồm: CYP2E1 $3739 \mathrm{G}>\mathrm{C}, 3620 \mathrm{C}>\mathrm{T}, 3519 \mathrm{~T}>\mathrm{G}$, $3468 \mathrm{~T}>\mathrm{A}$. Các đa hình được trình bày trong Hình 2.

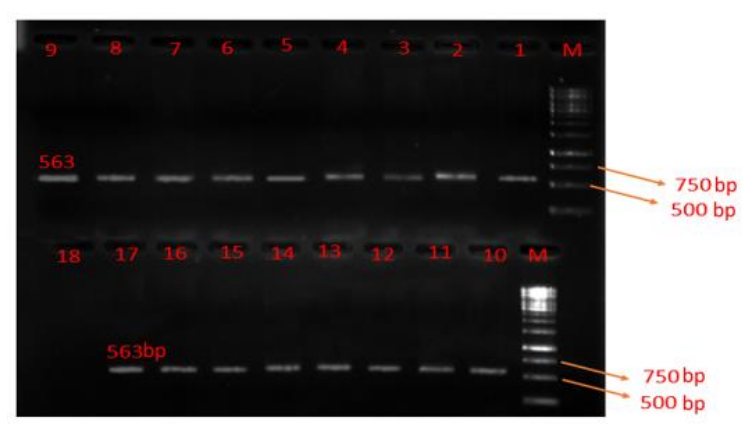

Hình 1. Kết quả điện di sản phẩm PCR khuếch đại đoạn promoter của gen $C Y P 2 E 1$.

Chú thích: M: marker 1kb; 1-17: các mẫu nghiên cứu; 18: mẫu đối chứng âm

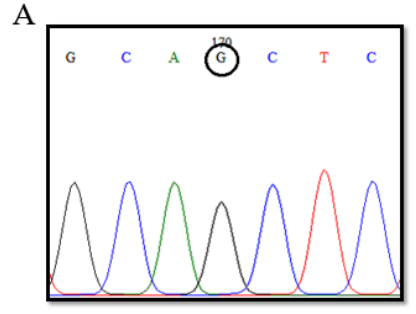

(a)

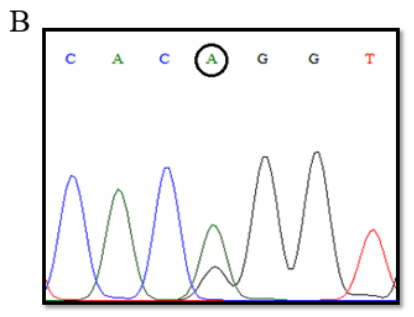

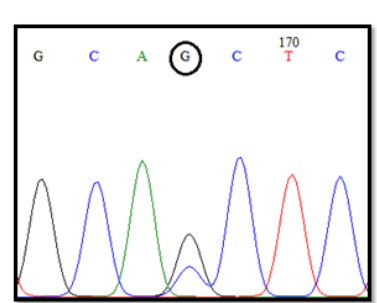

(b)

$\mathrm{D}$

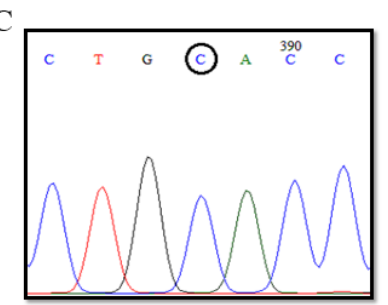

(a)

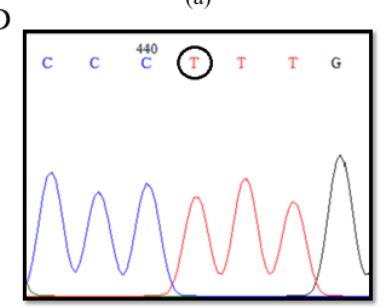

(a)

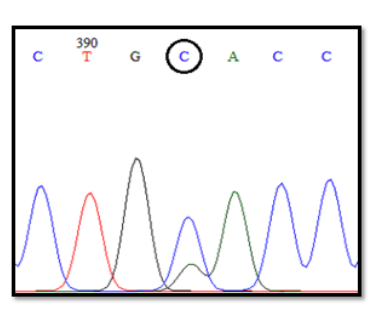

(b)

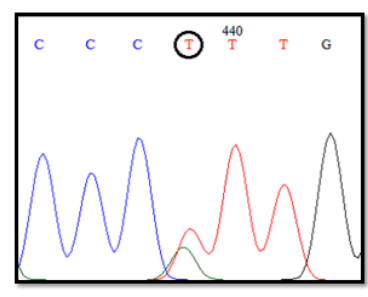

(b)

Hình 2. Những điểm đa hình trên trình tự promoter $C Y P 2 E 1$.

Chú thích: (A) Alen $\mathrm{G}$ của gen $C Y P 2 E 1$ ở mẫu được giải trình tự với mồi ngược, tương ứng với alen $\mathrm{C}$ của CYP2E1 3739G $>\mathrm{C}$; (B) Alen A của gen CYP2E1 của mẫu được giải trình tự với mồi ngược, tương ứng với alen $\mathrm{T}$ của $C Y P 2 E 13620 \mathrm{C}>\mathrm{T}$; $(\mathrm{C})$ Alen $\mathrm{C}$ của gen $C Y P 2 E 1$ của mẫu được giải trình tự với mồi ngược, tương ứng với alen $\mathrm{G}$ của $C Y P 2 E 13519 \mathrm{~T}>\mathrm{G}$ và $(\mathrm{D})$ Alen $\mathrm{T}$ của gen $C Y P 2 E 1$ của mẫu được giải trình tự với mồi ngược, tương ứng với alen $\mathrm{A}$ của $C Y P 2 E 13468 \mathrm{~T}>\mathrm{A}$ : (a) đồng hợp và (b) dị hợp.

Kiểu gen đồng hợp và dị hợp được phát hiện ở 3 trong số 4 điểm đa hình. Với locus đa hình CYP2E1 3620C>T, chỉ có kiểu gen dị hợp $\mathrm{CT}$ được xác định. Nguyên nhân có thể từ việc cỡ mẫu nghiên cứu chưa đủ lớn để có thể phát hiện được các kiểu gen khác. Tần số xuất hiện của các kiểu gen và alen cũng đã được phân tích thống kê, cho thấy nhóm mẫu nghiên cứu 
có tần số alen và kiểu gen theo cân bằng Hardy-Weinberg. Tần số alen và kiểu gen được

phân tích kết quả được thể hiện trong Bảng 3.

Bảng 3. Tần số alen và tần số kiểu gen trong quần thể nghiên cứu

\begin{tabular}{|c|c|c|c|c|c|}
\hline $\mathrm{TT}$ & $\begin{array}{l}\text { Vị trí } \\
\text { SNP }\end{array}$ & $\begin{array}{l}\text { Kiểu } \\
\text { gen/Alen }\end{array}$ & $\begin{array}{l}\text { Nhóm tiếp } \\
\text { xúc }(\mathrm{n} / \%)\end{array}$ & $\begin{array}{l}\text { Nhóm không } \\
\text { tiếp xúc (n/\%) }\end{array}$ & Giá trị p \\
\hline \multirow{5}{*}{1} & \multirow{5}{*}{$\begin{array}{l}3739 \\
\mathrm{G}>\mathrm{C}\end{array}$} & GG & $53(72,6)$ & $29(64,4)$ & \\
\hline & & GC & $16(21,9)$ & $15(33,3)$ & 0,21 \\
\hline & & $\mathrm{CC}$ & $4(5,5)$ & $1(2,3)$ & 0,48 \\
\hline & & $\mathrm{G}$ & $83,6 \%$ & $81 \%$ & \multirow{2}{*}{0,63} \\
\hline & & $\mathrm{C}$ & $16,4 \%$ & $19 \%$ & \\
\hline \multirow{5}{*}{2} & \multirow{5}{*}{$\begin{array}{l}3620 \\
\mathrm{C}>\mathrm{T}\end{array}$} & $\mathrm{CC}$ & $72(98,6)$ & 45 (100) & \multirow{2}{*}{0,43} \\
\hline & & $\mathrm{CT}$ & $1(1,4)$ & $0(0)$ & \\
\hline & & $\mathrm{TT}$ & $0(0)$ & $0(0)$ & \multirow{3}{*}{0,4} \\
\hline & & $\mathrm{C}$ & $99,3 \%$ & $100 \%$ & \\
\hline & & $\mathrm{T}$ & $0,7 \%$ & $0 \%$ & \\
\hline \multirow{5}{*}{3} & \multirow{5}{*}{$\begin{array}{l}3519 \\
\mathrm{~T}>\mathrm{G}\end{array}$} & $\mathrm{TT}$ & $21(28,8)$ & $13(28,9)$ & \\
\hline & & TG & $32(43,8)$ & $23(51,1)$ & 0,74 \\
\hline & & GG & $20(27,4)$ & $9(20)$ & 0,55 \\
\hline & & $\mathrm{T}$ & $50,1 \%$ & $54,4 \%$ & \multirow{2}{*}{0,54} \\
\hline & & G & $49,9 \%$ & $45,6 \%$ & \\
\hline \multirow{5}{*}{4} & \multirow{5}{*}{$\begin{array}{l}3468 \\
\mathrm{~T}>\mathrm{A}\end{array}$} & $\mathrm{TT}$ & $52(71,2)$ & $29(64,4)$ & \\
\hline & & TA & $14(19,2)$ & $13(28,9)$ & 0,25 \\
\hline & & AA & $7(9,6)$ & $3(6,7)$ & 0,31 \\
\hline & & $\mathrm{T}$ & $80,8 \%$ & $78,9 \%$ & \multirow{2}{*}{0,73} \\
\hline & & A & $19,2 \%$ & $21,1 \%$ & \\
\hline
\end{tabular}

Kết quả ở Bảng 3 cho thấy, ở các locus CYP2E1 3739G $>C, 3620 \mathrm{C}>\mathrm{T}$ và $3468 \mathrm{~T}>\mathrm{A}$, tần số các kiểu gen và tần số alen của alen kiểu dại (tương ứng chứa $\mathrm{G}, \mathrm{C}$ và $\mathrm{T}$ ở ba locus) đều cao hơn so với alen đột biến (tương ứng với alen $\mathrm{C}$, $\mathrm{T}$ và $\mathrm{A})$, ở cả nhóm đối chứng và nhóm tiếp xúc dung môi hữu cơ. Tại locus CYP2E1 3519T >G, kiểu gen dị hợp TG chiếm tần số lớn nhất (43,8\%), ở nhóm công nhân bị phơi nhiễm dung môi hữu cơ và $51,1 \%$ ở nhóm không phơi nhiễm; tần số alen $\mathrm{T}$ gần như tương đương $(50,1 \%)$ so với alen $\mathrm{G}(49,9 \%)$. Khi phân tích mối liên quan giữa việc tiếp xúc với dung môi và tần số alen, tần số kiểu gen của các vị trí đa hình, số liệu thu được cho thấy sự khác biệt về tần số kiểu gen giữa hai nhóm đối tượng nghiên cứu là không có ý nghĩa $(\mathrm{P}>0,05)$. Do vậy, sự phơi nhiễm VOC không liên quan đến tần số kiểu gen, tần số alen ở các vị trí đa hình này.
Khi so sánh trên ngân hàng gen các biến thể di truyền dbSNP Short Genetic Variations của NCBI website cho thấy, các SNP 3739G $>$ C, $3620 \mathrm{C}>\mathrm{T}, 3468 \mathrm{~T}>\mathrm{A}$ và $3519 \mathrm{~T}>\mathrm{G}$ có mã số tương ứng là rs3813867, rs11575870, rs8192766 và rs3813866. Trong nghiên cứu của Zhu và cộng sự tần số của đa hình mã rs3831867 có sự khác biệt ở người Kinh tại thành phố Hồ Chí Minh, Việt Nam với tần số $\mathrm{C}$ là 0,2172 cao gấp 10 lần so với tần số alen $\mathrm{C}$ tại quần thể Iberia ở Tây Ban Nha $(0,0234)$, gấp 20 lần ở quần thể Pakistan $(0,0104)$ và có kêt quả tương tự với một số nước lân cận như quần thể Nhật Bản $(0,1923)$ và Trung Quốc $(0,1613)$. Tần số alen $\mathrm{T}$ của đa hình mã rs 11575870 chỉ xuất hiện ở quần thể Xishuangbanna, Trung Quốc là 0,0054 và quần thể người sống tại thành phố Hồ Chí Minh, Việt Nam là 0,0051 . 
Trong nghiên cứu này, tần số biến thể $\mathrm{G}$ của đa hình mã rs8192766 có sự khác nhau giữa các quốc gia và các châu lục. Cụ thể ở 2 tộc người ở Trung Quốc: tộc người Xishuangbanna có tần số alen $\mathrm{G}$ (biến thể) là 0,5538 ; ở tộc người Hán sống ở Bắc Kinh Trung Quốc tần số G là 0,45 ; Người ở Nam Hán có tần số của alen G là 0,42 , tương tự với kết quả của một số nước lân cận như Nhật Bản là 0,456 , thành phố Hồ Chí Minh là 0,56 và có sự khác biệt hoàn toàn với quần thể người Utah $(\mathrm{CEPH})$ với tổ tiên Bắc Âu và Tây Âu có alen biến thể $\mathrm{G}$ có tần số là 0,1061 ; với quần thể người Anh ở Anh và Scotland tần số $\mathrm{G}$ là $0,0549 \ldots[9,10]$.

Đối với đa hình mã rs3813866, tần số biến thể $\mathrm{A}$ cũng được so sánh với các quần thể khác nhau cụ thể tần số có kết quả tương đương nhau thu được ở các quần thể người Kinh ở thành phố Hồ Chí Minh 0,2172; quần thể người Trung Quốc 0,2379 ; quần thể Nhật Bản 0,1923 và có sự cách biệt rõ rệt đối với quần thể Ân Độ 0,0091 ; quần thể người Pakistan 0,01 gấp 20 lần [9],[10]. Tuy nhiên 4 điểm này lại chưa được công bố trên đối tượng người lao động trong ngành sản xuất sơn, có tiếp xúc trực tiếp với benzen, toluen, xylen, styren.

Kết quả tương tự cũng được công bố trong các nghiên cứu của Wan [8], Chen và cộng sự [11], Lan và cộng sự [12], và Simone và cộng sự [13]. Tuy nhiên sự có mặt của các đa hình CYP2E1 lại có ảnh hưởng đến nguy cơ của một số bệnh trong quần thể bị phơi nhiễm với dung môi hữu cơ. Zhang và cộng sự đã đề cập đến vị trí đa hình mã rs3813867 ở những đối tượng có chứa alen biến thể có hiện tượng giảm đáng kể số lượng bạch cầu trong nhóm bị phơi nhiễm dung môi hữu cơ. Trong nghiên cứu khác về phơi nhiễm với benzen, Zhang kết luận rằng có mối liên quan giữa đa hình rs3813867 với tình trạng hút thuốc lá. Việc hút thuốc đã làm cho các cá nhân mang biến thể có nguy cơ nhiễm độc benzen cao gấp 4 lần [14].

Mặt khác, đa hình nằm trên vùng điều hòa của gen $C Y P 2 E 1$ ảnh hưởng đến sự liên kết của các nhân tố phiên mã và làm thay đổi sự điều hòa phiên mã, những sự thay đổi này có thể được giải thích thông qua mức độ biểu hiện của
CYP2E1 mRNA [7]. Trong nghiên cứu của Hayashi và cộng sự cho thấy với đa hình mã rs3831867 có mức độ biểu hiện của gen CYP2E1 cũng tăng 10 lần so với đối chứng [7]. Các nghiên cứu của Ekstrom và cộng sự; Wrighton và cộng sự đều cho rằng sự biến đổi trên $C Y P 2 E 1$ có thể làm tăng biểu hiện $C Y P 2 E 1$ ở gan [15]. Nghiên cứu của Johnsrud và cộng sự, Itoga và cộng sự đã báo cáo vùng mã hóa của $C Y P 2 E 1$ được bảo toàn cao và có khả năng là sự thay đổi có liên quan đến các đa hình trong vùng promoter [15].

\section{Kết luận}

Mặc dù chưa tìm ra được mối liên hệ giữa 4 đa hình tìm được trên trình tự của đoạn promoter của gen $C Y P 2 E 1$ ở đối tượng công nhân làm việc tại công ty sản xuất sơn bị phơi nhiễm với các dung môi hữu cơ như benzen, toluen, xylen, styren ở Việt Nam, nhưng việc phát hiện và phân tích các đa hình trên trình tự promoter của gen $C Y P 2 E 1$ có ý nghĩa trong nghiên cứu về mức độ biểu hiện gen và sự ảnh hưởng đến sức khỏe của những công nhân làm trong ngành công nghiệp này nhằm đảm bảo và tăng cường sự an toàn nghề nghiệp của người lao động.

\section{Lời cảm ơn}

Nghiên cứu được hỗ trợ kinh phí bởi đề tài nghiên cứu Khoa học và Công nghệ năm 2016 "Nghiên cứu ảnh hưởng mạn tính của benzen, toluen, xylen ở người lao động tiếp xúc với nồng độ dưới tiêu chuẩn cho phép qua xét nghiệm một số chỉ số huyết học, chỉ số mRNA $C Y P 2 E 1$ và sự biến đổi của gen $C Y P 2 E 1$ " Mã số 216/09/TLĐ.

\section{Tài liệu tham khảo}

[1] Junko W., Hayashi S., Kaname K. (1994), Different Regulation and Expression of the Human CYP2E1 Gene Due to the Rsal Polymorphism in the 5-Flanking, J. Biochem, 116, 321-326. 
[2] Peter R., Bocker R., Beaune P.H., Iwasaki M., Guengerich F.P., et al. (1990), Hydroxylation of chlorzoxazone as a specific probe for human liver cytochrome P 450IIE1, Chem Res Toxicol, 3, 566-573.

[3] Guengerich F.P., Kim D.H., Iwasaki M. (1991), Role of human cytochrome P-450 IIE1 in the oxidation of many low molecular weight cancer suspects, Chem Res Toxicol, 4, 168-179.

[4] Kharasch E.D., Thummel K.E. (1993), Identification of cytochrome P450 2E1 as the predominant enzyme catalyzing human liver microsomal defluorination of sevoflurane, isoflurane, and methoxyflurane, Anesthesiology, 79, 795-807.

[5] Lieber C.S. (1997), Cytochrome P-4502E1: its physiological and pathological role,Physiol Rev, 77, 517-544.

[6] Bolt H.M., Roos P.H., Thier R. (2003), The cytochrome $\mathrm{P}-450$ isoenzymeCYP2E1 in the biological processing of industrial chemicals: consequences for occupational and environmental medicine, Int Arch Occup Environ Health,76, 174-185.

[7] Hayashi S., Watanabe J., Kawajiri K. (1991), Genetic polymorphisms in the 5 prime flanking region change transcriptional regulation of the humancytochrome P450IIE1 gene, J. Biochem, 110, 559-565.

[8] Wan J., Shi J., Hui L., Wu D., Jin X., Zhao N., Huang W., Xia Z. (2002), Association of genetic polymorphisms in
CYP2E1, MPO, NQO1, GSTM1, and GSTT1genes with benzene poisoning, Environ. Health Perspect, 110, 1213-1218.

[9] Linhao Z., Yongjun H., Fanglin N. et al. (2018), Polymorphisms of drug-metabolizing enzymeCYP2E1 in Chinese Uygur population, Medicine, 97(7), p. e9970

[10] https://www.ncbi.nlm.nih.gov/.

[11] Chen Y., Li G., Yin S. et al.(2007), Genetic polymorphisms involved in toxicant-metabolizing enzymes and the risk of chronic benzene poisoning in Chinese occupationally exposed populations, Xenobiotica, 37(1), 103-112.

[12] Lan Q., Zhang L., Li G. et al.(2004), Hepatotoxicity in workers exposed to low levels of benzene, Science, 306 (5702), 1774-1776.

[13] Mitri S., Fonseca A.S.A, Otero U.B. et al.(2015), Metabolic polymorphisms and clinical findings related to benzene poisoning detected in exposed Brazilian gas-station workers, Int.J.Environ. Res.Public Health, 12 (7), 8434-8447.

[14] Zhang G.H., Ye L.L., Wang J.W. et al. (2014), Effect of polymorphic metabolizing genes on micronucleus frequencies among benzeneexposed shoe workers in China,Int.J.Environ.Res.Public Health,217(7), 726-732.

[15] Huang X., Chen L., Song W. et al.(2012), Systematic functional characterization of cytochrome P450 2E1 promoter variants in the Chinese Han population, PloS one, 7(7), p. e40883.

\title{
Genetic Polymorphism in Promoter Sequence of CYP2E1 Gene in Paint Manufacturing Workers Exposed to Volatile Organic Compounds
}

\author{
Nguyen Thi Hien ${ }^{1,2}$, Do Thi Cam Nhung ${ }^{1}$, Nguyen Phu Hung ${ }^{3}$, \\ Nguyen Thi Hong Van ${ }^{1}$, Bui Phuong Thuan ${ }^{1}$, Nguyen Quang Huy ${ }^{1}$ \\ ${ }^{I}$ Faculty of Biology, VNU University of Science, 334 Nguyen Trai, Thanh Xuan, Hanoi, Vietnam \\ ${ }^{2}$ Vietnam National Insitute of Occupational Safety and Health, 99 Tran Quoc Toan, Hanoi, Vietnam \\ ${ }^{3}$ Thai Nguyen University of Sciences, Thai Nguyen, Vietnam
}

\begin{abstract}
Enzyme CYP2E1 plays an important role in the metabolism and bio-activation of volatile organic compounds (VOCs) such as benzene, toluene, xylene (B, T, X), commonly used in the industry. The presence of the polymorphism in the promoter region of CYP2E1 gene may lead to
\end{abstract}


changes in gene expression and the progression of some diseases in people exposed to VOCs. This study analyzes the polymorphism of CYP2E1 promoter which can affect the expression of this gene and is related to the accumulation of toxic products in 118 participants including 73 workers of the exposed group from paint manufacturing factories and 45 workers of the non-exposed group from garment factories by using Polymerase Chain Reaction and DNA sequencing methods. The results show that the expected DNA fragment was amplified in all the samples and 4 polymorphic $3739 \mathrm{G}>\mathrm{C}$, 3620C $>\mathrm{T}, 3519 \mathrm{~T}>\mathrm{G}$, and 3468T $>\mathrm{A}$ were observed. The relationship between these SNPs of CYP2E1 and the exposure of VOCs is not shown. However, there was heterogeneity in CYP2E1 genotype among the studied subjects.

Keywords: Single nucleotide polymorphism, CYP2E1, metabolism of volatile organic compounds. 